\title{
Correction to: Special Multifunctional Adverbs (II)
}

\section{Correction to:}

\section{Chapter 8 in: S. Cui, K.-m. Sung, A Reference Grammar for Teaching}

Chinese, https://doi.org/10.1007/978-981-33-4207-1_8

This chapter was inadvertently published with incorrect spelling in the title which has now been corrected to "Special Multifunctional Adverbs (II)". 